\title{
Novel esophageal reconstruction technique via transmediastinal route from posterior to anterior mediastinum after esophagectomy
}

Takushi Yasuda, MD, ${ }^{a}$ Osamu Shiraishi, MD, ${ }^{a}$ Mitsuru Iwama, MD, ${ }^{a}$ Tomoki Makino, MD,

Hiroaki Kato, MD, ${ }^{a}$ and Yutaka Kimura, MD $^{\mathrm{a}}$

\section{ABSTRACT}

Background: The incidence of metachronous esophageal squamous cell cancer (ESCC) after head and neck cancer (HNC) and in elderly patients has increased. Both elderly ESCC patients and ESCC patients after HNC surgery are at potential risk for dysphagia, and for the latter, surgery in the neck is difficult. An intrathoracic anastomosis that bypasses the cervical procedure is preferable to preserve swallowing function and reduce surgical risk. In gastrectomized patients, because the stomach cannot be used as a substitute, securing graft blood supply is critical, but microvascular anastomosis cannot be easily added in procedures for intrathoracic posterior mediastinal reconstruction. Thus, we have developed a novel technique for esophageal reconstruction in gastrectomized patients who are elderly or who had undergone HNC surgery, enabling concomitant intrathoracic anastomosis and microvascular anastomosis. The purpose of this study was to evaluate the usefulness and safety of this technique.

Methods: The jejunal or ileocolic graft is first pulled up through the anterior mediastinum and is then passed into the right thoracic cavity via a small hole made in the anterior mediastinal pleura. The graft is finally anastomosed with the remnant esophagus in the upper posterior mediastinum. Thereafter, microvascular anastomosis is performed in the retrosternal space.

Results: Four patients underwent this new reconstruction procedure with no significant postoperative complications, good swallowing function postoperatively, and no retention of food in the graft.

Conclusions: This novel transmediastinal reconstruction technique is a possible option for highly selected patients to enable intrathoracic anastomosis and the addition of microvascular anastomosis. (J Thorac Cardiovasc Surg 2018;156:859-66)

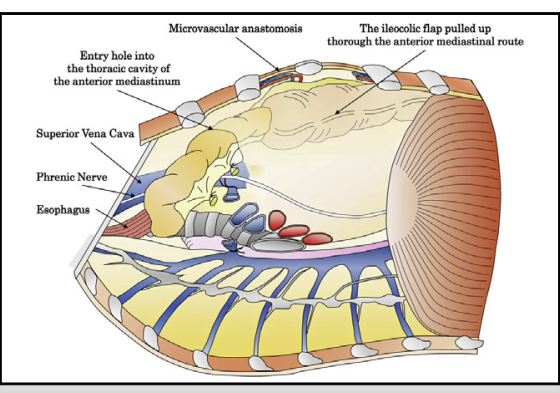

Novel transmediastinal esophageal reconstruction with the ileocecal graft.

\section{Central Message}

Novel esophageal reconstruction crossing the mediastinum from the posterior to the anterior with a jejunal or colonic graft enables both intrathoracic anastomosis and microvascular anastomosis.

\section{Perspective}

With improving surgical outcomes and societal aging, the number of elderly patients with esophageal cancer developing after surgery for head and neck cancer or stomach cancer is increasing. In such patients, swallowing function deteriorates and a cervical procedure is difficult. An intrathoracic anastomosis is the preferred approach, but securing the blood flow of the graft is vital. For those cases, our technique will be the solution.

See Editorial Commentary page 867
Smoking, alcohol consumption, and male sex are wellknown risk factors for head and neck cancer (HNC) as

\footnotetext{
From the a Department of Surgery, Faculty of Medicine, Kindai University, Osaka, Japan; and ${ }^{\mathrm{b}}$ Department of Gastroenterological Surgery, Graduate School of Medicine, Osaka University, Osaka, Japan.

Received for publication Oct 31, 2017; revisions received March 14, 2018; accepted for publication March 25, 2018; available ahead of print May 9, 2018.

Address for reprints: Takushi Yasuda, MD, Department of Surgery, Faculty of Medicine, Kindai University, 377-2 Ohno-Higashi, Osaka-Sayama, Osaka 589-8511, Japan (E-mail: takushi-yasuda6008@med.kindai.ac.jp). 0022-5223/\$36.00

Copyright (C) 2018 by The American Association for Thoracic Surgery https://doi.org/10.1016/j.jtcvs.2018.03.161
}

well as esophageal squamous cell cancer (ESCC). With recent improvements in surgical outcomes for $\mathrm{HNC}$, the incidence of metachronous ESCC after HNC has increased, ${ }^{1}$ reaching up to $24.1 \%$ in the annual report of esophageal cancer in Japan. ${ }^{2}$ The cervical procedure after

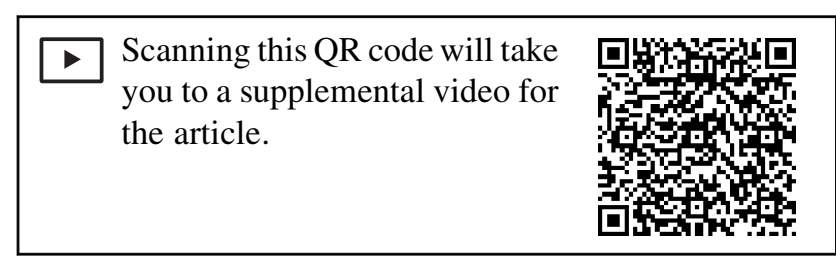




\section{Abbreviations and Acronyms}

$\mathrm{AM}=$ anterior mediastinum

$\mathrm{ESCC}=$ esophageal squamous cell cancer

$\mathrm{HNC}=$ head and neck cancer

ITV $=$ internal thoracic vessel

$\mathrm{PM}=$ posterior mediastinum

surgery for HNC is very complicated, however, especially for dissection of the esophagus and the membranous portion of the tracheal stoma. In addition, approximately $40 \%$ of patients with ESCC are aged $>70$ years ${ }^{3}$ and are likely to have a potential risk of aspiration because of a diminished swallowing reflex due to subclinical cerebral infarction. ${ }^{4-7}$ Even for younger patients, the cervical procedure for esophagogastrostomy is likely to induce postoperative swallowing dysfunction. ${ }^{8,9}$

Given the aforementioned difficulties and risks, the cervical procedure should be circumvented in such high-risk cases when at all oncologically acceptable. The preferred approach is to perform intrathoracic anastomosis following gastric pull-up via the posterior mediastinum (PM). However, in patients who have previously undergone gastrectomy, esophageal reconstruction requires a jejunal or colonic graft. Blood flow to the graft is not always sufficient, however, and some form of microvascular augmentation is needed in some cases to prevent postoperative graft necrosis, ${ }^{10,11}$ which is likely fatal when occurring in the PM. However, the addition of microvascular anastomosis is next to impossible in a conventional intrathoracic anastomosis for PM reconstruction.

To address this issue, we have designed a novel esophageal reconstruction technique that allows for both a high intrathoracic anastomosis using a jejunal or colonic graft in the PM and the addition of microvascular anastomosis between the internal thoracic vessels (ITVs) in the anterior mediastinum (AM) and the vessels of the graft (Figure 1). Here we present our experience performing this innovative esophageal reconstruction in 4 highly selected patients, which provided satisfactory results.

\section{PATIENTS AND METHODS \\ Patients}

Among 544 patients who underwent esophagectomy for esophageal cancer between 2009 and 2016 at Kindai University Hospital, patients who met the following criteria were eligible for our novel esophageal reconstruction technique: (1) tumor located in the middle or lower third of the thoracic esophagus, (2) no lymph node metastasis in the neck or upper mediastinum, (3) history of previous partial or total gastrectomy, (4) adequate hematologic and organ function, (5) absence of severe mental disorder, 6) operable through a right thoracotomy, (7) past history of surgery or radiation therapy for $\mathrm{HNC}$ or cerebrovascular disease or advanced age, and (8) provision of written informed consent. Eventually, 4 patients were selected and underwent our new surgical procedure.

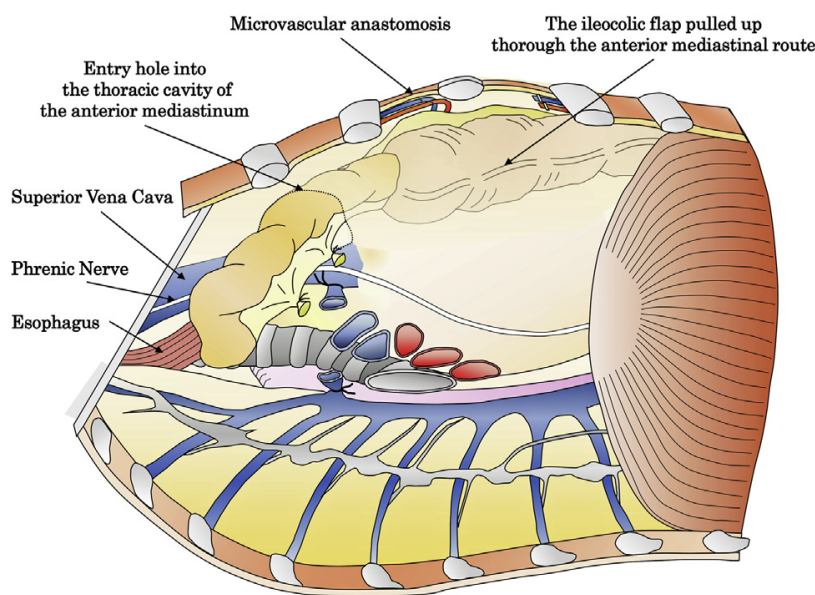

FIGURE 1. Illustration showing the transmediastinal (ie, posterior $\rightarrow$ anterior mediastinum) reconstruction with ileocolic flap. The esophagoileostomy and microvascular anastomosis between the right internal iliac and the ileocecal vessels are shown.

\section{Surgical Procedure}

The procedure consists of 9 steps. The first step comprises esophagectomy accompanied by mediastinal lymphadenectomy performed through a right thoracotomy with the patient in the left lateral decubitus position. The esophagus is first divided at the upper mediastinum with safe surgical margins using a linear stapler, after which temporary chest closure is performed. In the second step, the patient is placed in the a half side-lying position and then supine position using a bed-rotating technique. In patients who had undergone partial gastrectomy, the remnant stomach is resected along with upper abdominal lymph node dissection; in those who had undergone total gastrectomy, the jejunal loop is mobilized and cut off the jejunojejunostomy of the Roux-en-Y loop. Next, the distal segment of the esophagus is pulled out from the thoracic cavity into the abdominal cavity through the esophageal hiatus and excised.

The third step entails creating a pedicle graft. Our first choice for an esophageal substitute is the jejunum. The long pedicled jejunal flap is created by severing the second and third jejunal mesenteric vessels and in some cases, the fourth when necessary, in the same way as in the conventional jejunal reconstruction technique. Alternatively, a pedicled ileocolic flap is used if creating a jejunal flap with adequate neck length is anticipated to be difficult.

For the fourth step, the graft is initially pulled up to the neck and placed on the skin of the anterior chest wall, assuming the position being dropped down from the AM and the distance from that point to the anastomosis site in the PM (Figure 2). In that state, the location of microvascular anastomosis between the right ITVs and the jejunal mesenteric vessels or the ileocecal vessels or its marginal vessels is determined, followed by resection of 1 or 2 costal cartilages positioned at the microvascular anastomosis site, exposing the right ITVs and reserving surgical space for microvascular anastomosis (Figure 3, A).

The fifth step involves creating an AM route from the xiphoid process to below the sternal notch with an intestinal spatula. The patient's position is changed from supine to left decubitus, and a repeat thoracotomy is performed. On insertion of an intestinal spatula into the AM route, the tip of the spatula can be readily visualized through the right AM pleura (Figure 4, A), and a longitudinal incision of several centimeters is made through the thoracotomy, guided by the intestinal spatula (Figure 4, B). These procedures to enlarge the AM space produce free space behind the ITVs and reveal the interior of the AM route through the space between the ITVs and the stumps of the resected ribs. 


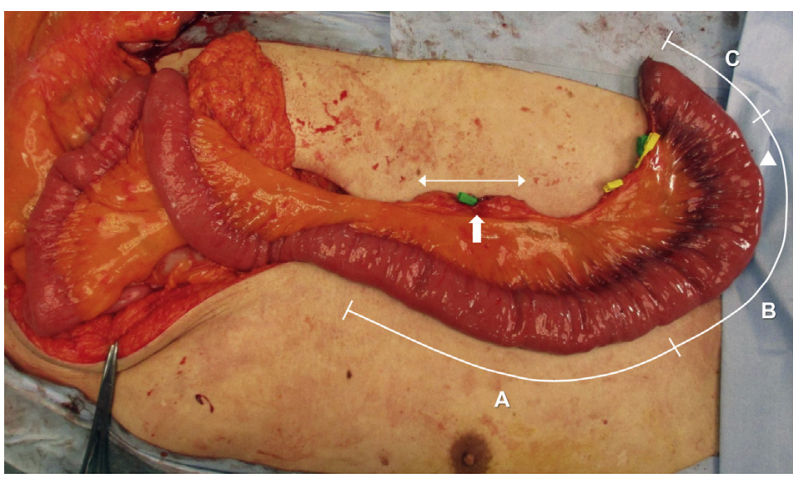

FIGURE 2. Intraoperative image placing the pedicled jejunal graft on the skin of the anterior chest wall in patient 3. Regions A, B, and C show the jejunal parts that will be placed in the AM route and in the right thoracic cavity, and resected after esophagojejunostomy, respectively. The closed triangle indicates the planned location of the esophagojejunostomy; the closed arrow, mesenteric vessels for microvascular anastomosis; the double-headed arrow, skin incision to resect the costal cartilage for microvascular anastomosis.

Next, the graft is elevated through the AM, holding the surgical thread fixed at the tip of the graft with a long Kelly forceps. When visualized within the small hole in the upper AM pleura (Figure 4,C), the surgical thread is grasped with long tweezers, and the graft is pulled into the right thoracic cavity (Figure 4,D). During these procedures, the position and condition of the graft and the mesentery are monitored; pulling of the graft is stopped when the vessels of the graft for microvascular anastomosis are positioned at the center of the space produced by resection of the costal cartilage (Figure 3, $B$, and Video 1).
In the sixth step, anastomosis with the remnant esophagus is performed by using a circular stapler through the right thoracotomy. The anastomotic site is covered with the upper mediastinal pleura preserved in advance for the purpose of reinforcement, when possible. The seventh step entails fixing the graft in the right thoracic cavity on the mediastinal pleura with absorbable surgical sutures to prevent stasis of that segment by sagging, kinking, and torsion (Figure 5 and Video 1), followed by sterile saline washing of the thoracic cavity and then chest closure. In the eighth step, the patient is returned to the supine position, and microvascular anastomosis is performed between the right ITVs and the vessels of the graft by a plastic surgeon at the site where the costal cartilage had been resected in advance (Figure 3,C). In the ninth and final step, the continuity of the alimentary tract is restored.

\section{RESULTS}

\section{Patient Backgrounds}

This surgical procedure was performed for 4 patients, all of whom had a previous history of gastrectomy due to gastric cancer $(\mathrm{n}=3)$ or gastric ulcer $(\mathrm{n}=1)$ (Table 1$)$. Past medical history and the reason for adopting our novel reconstruction method for each case are as follows.

Patient 1 underwent cervical esophagectomy with free jejunal reconstruction after neoadjuvant chemoradiotherapy with $30 \mathrm{~Gy}$ and distal gastrectomy with Billroth-I reconstruction to treat double cancer of the cervical esophagus and the stomach. Postoperative adjuvant chemoradiotherapy with $30 \mathrm{~Gy}$ was added because of the T4 tumor invading the cervical prevertebral fascia as well as the larynx. Three years later, ESCC of the lower third of the esophagus with cStage IA of cT1bNOM0 was detected. Cervical and upper mediastinal lymphadenectomies were already completed in
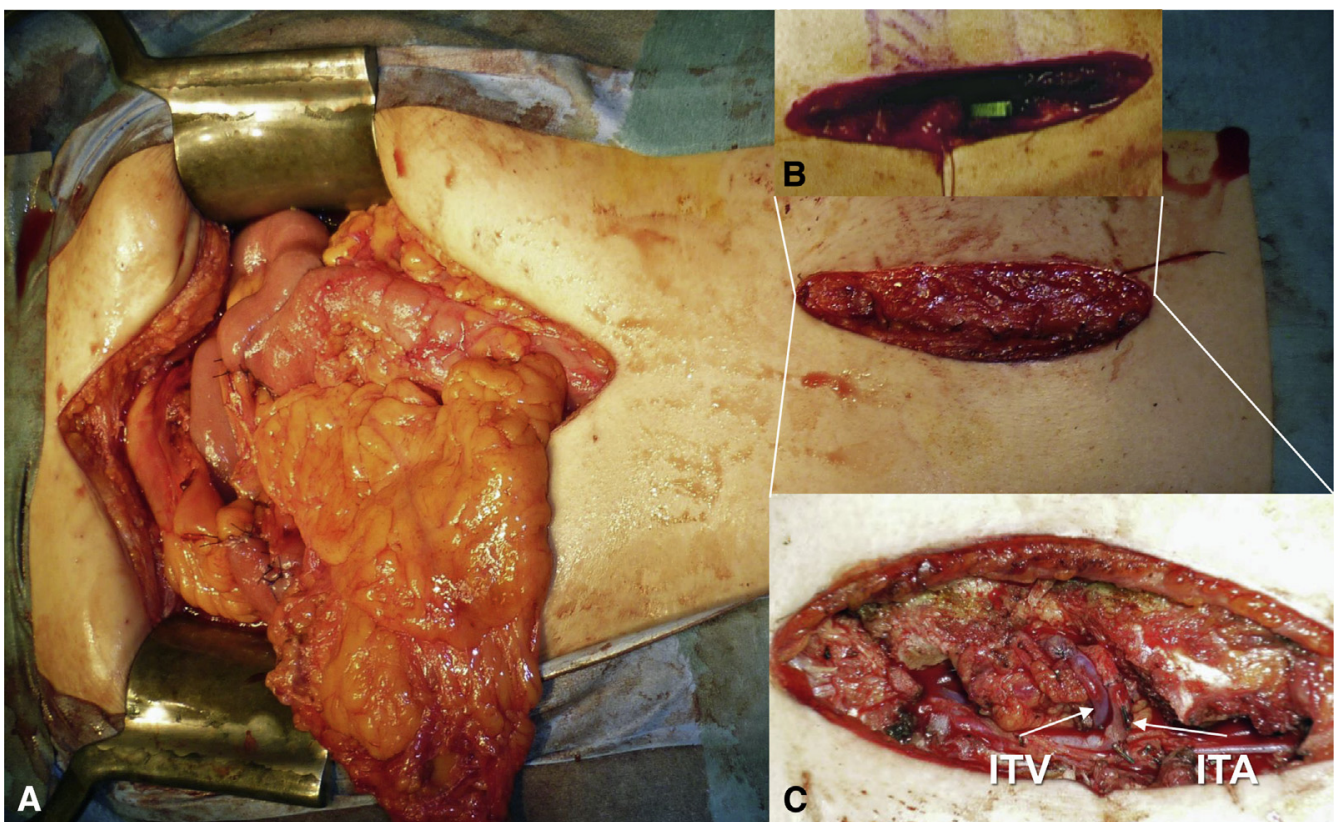

FIGURE 3. Intraoperative image of patient 1 , who underwent ileocolic reconstruction and microvascular anastomosis. A, Skin incision for microvascular anastomosis. B, Disposable vessel clip for microvascular anastomosis can be seen in the center of the incision. C, Completion of microvascular anastomosis. ITV, Internal thoracic vein; ITA, internal thoracic artery. 

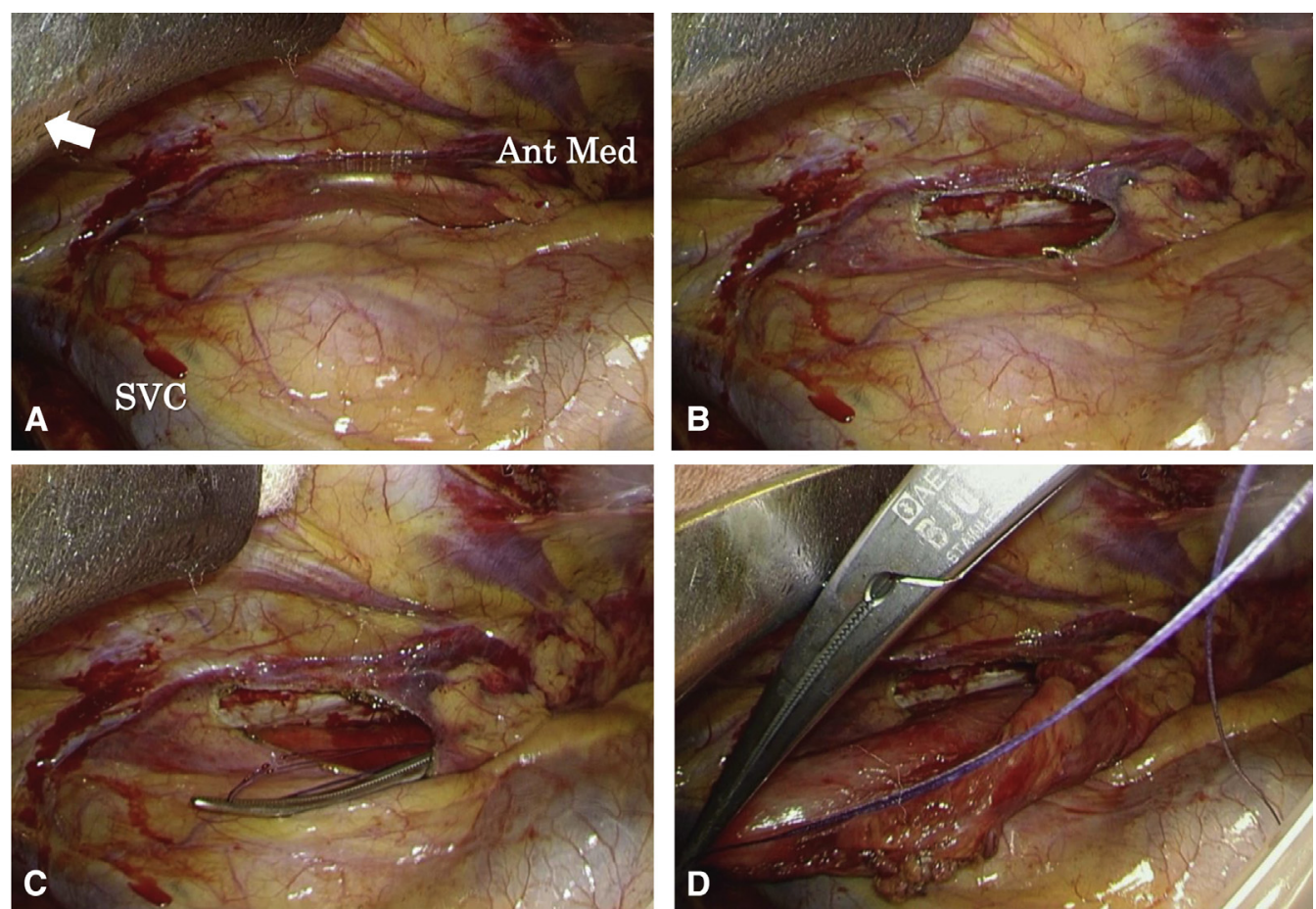

FIGURE 4. Intraoperative images of pulling up the graft through the anterior mediastinal route to the right thoracic cavity in patient 3 . A, The tip of the spatula can be recognized thorough the anterior mediastinal pleura. B, A longitudinal incision of the anterior mediastinal pleura is made. C, A surgical thread fixed at the tip of the graft is directed from the anterior mediastinal route to the right thoracic cavity with a long Kelly forceps. D, The graft is pulled down into the right thoracic cavity using the surgical thread. The closed arrow indicates the cranial direction. Ant Med, Anterior mediastinum; SVC, superior vena cava.

the previous surgery. However, the esophagus below the level of anastomosis with the free jejunal graft required resection. As a result, intrathoracic anastomosis at the top of the upper mediastinum with a long pedicled ileocolic flap was required.

Patient 2 had a previous history of surgery, including laryngectomy for laryngeal cancer as well as gastrectomy for gastric ulcer. Unfortunately, the sutures at the

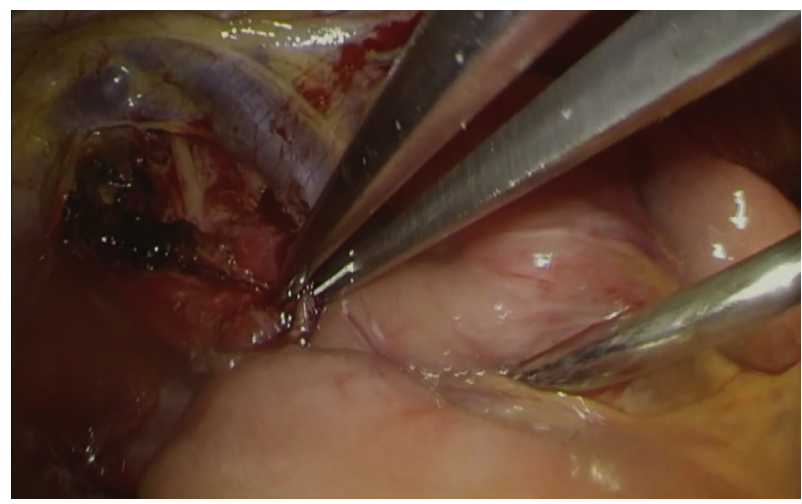

VIDEO 1. Procedures ranging from pulling down from the anterior mediastinal route to the right thoracic cavity to completion of esophagojejunostomy and fixation of the graft. Video available at: https://www.jtcvs.org/ article/S0022-5223(18)30984-X/fulltext. pharyngoesophageal closure failed after laryngectomy, resulting in formation of a fistula, which was repaired with a left pectoralis major musculocutaneous flap. Thus, performing another cervical procedure appeared to be almost impossible in this patient. In addition, right segmentectomy was later performed for a lung tumor, which was diagnosed as tuberculoma postoperatively. The patient developed advanced T3 ESCC straddling the junction of the middle and lower thirds of the thoracic esophagus. In this case, an intrathoracic anastomosis in the upper mediastinum was needed, but anastomotic failure, let alone graft necrosis, was unacceptable, given the extreme difficulty of a cervical procedure.

Patient 3 underwent total gastrectomy with $\mathrm{D} 2$ dissection for gastric cancer of the cardia (pT2N0M0, pStage IB). Lower mediastinal esophagojejunostomy was performed in view of esophageal invasion by poorly differentiated adenocarcinoma. Nevertheless, 5 years later, recurrence was observed as a submucosal tumor in the oral side of the esophagojejunostomy. Because of the possibility of submucosal esophageal spread, resection of the thoracic esophagus below the level of the azygos arch with mediastinal lymphadenectomy below the tracheal bifurcation was required, but the upper mediastinal lymphadenectomy, let alone the cervical lymphadenectomy, was needless oncologically. Therefore, the anastomosis had to be performed 

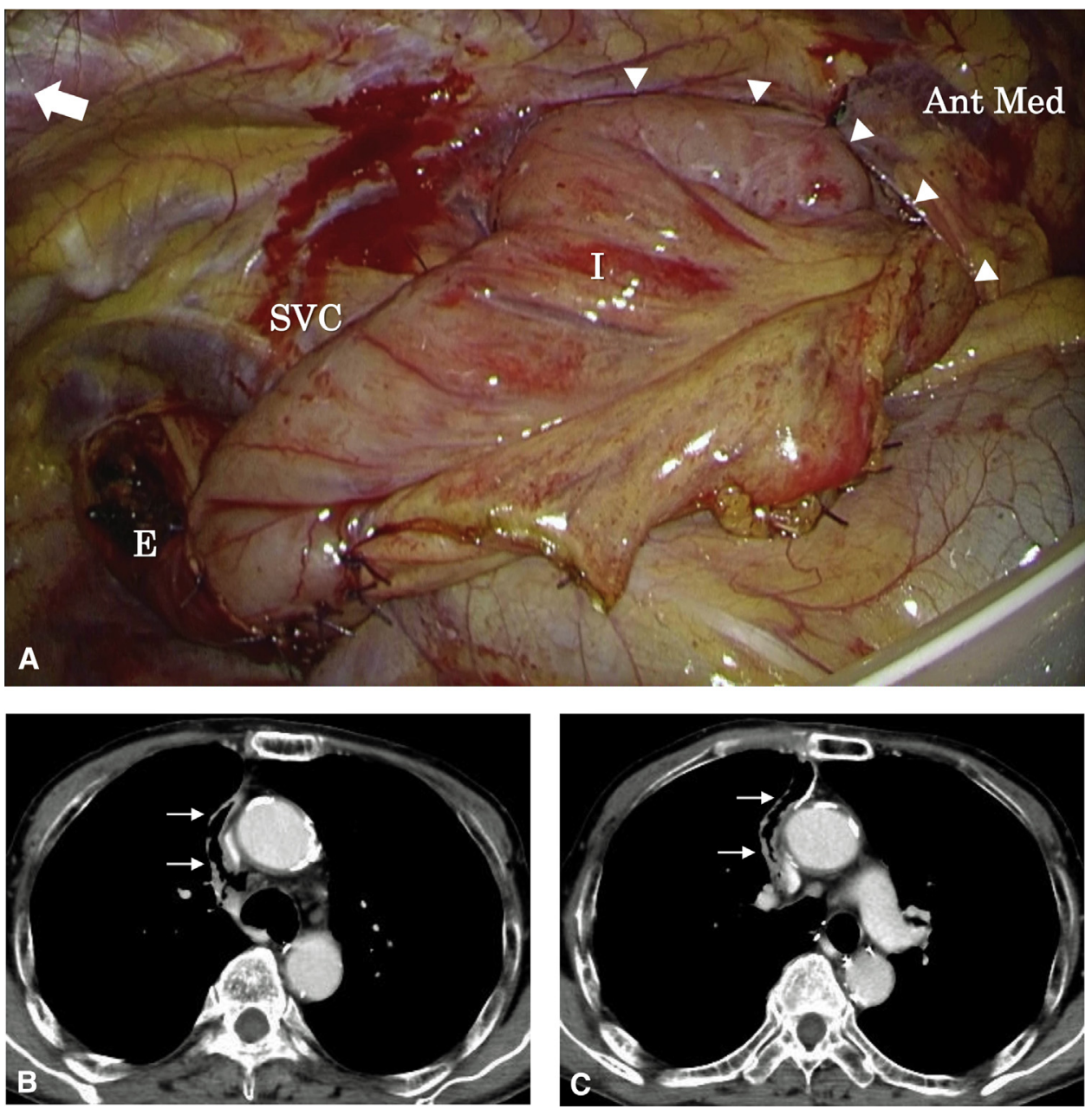

FIGURE 5. A, Intraoperative image of completion of the esophagojejunostomy in the upper thoracic cavity. B and C, Axial images of postoperative chest computed tomography in patient 3 . The jejunal flap is passed across the upper mediastinum from the posterior to the anterior aspect (arrows in B and C). The closed arrow indicates the cranial direction; the closed triangle indicates the entry hole into the thoracic cavity of the anterior mediastinum. Ant Med, Anterior mediastinum; $S V C$, superior vena cava; $E$, esophagus.

in the upper mediastinum, and thus the jejunal graft needed to be pulled up higher.

Patient 4 had previously undergone distal gastrectomy with Billroth-I reconstruction due to gastric cancer. Six years later, ESCC was detected in the lower third of the thoracic esophagus. By that time, he was age 83 years, and his swallowing reflex was likely reduced. Given the patient's diminished postoperative swallowing function and absence of clinically detected lymphadenopathy, the goal was to preserve the cervical muscles involved in swallowing.

\section{Surgical Outcomes}

Esophageal reconstruction was performed with an ileocolic graft in 2 patients and a jejunal graft in 2 patients (Table 2). Microvascular anastomosis was added in all cases. Anastomosis with the remnant esophagus was performed by a circular stapling technique in all patients except patient 1 , in whom the distal end of the free jejunum was in the upper aspect of the mediastinum, with a very narrow space between the trachea and the thoracic vertebra after the remnant esophagus was totally resected, hindering use of the anvil-headed circular stapler. Consequently, hand-sewn anastomosis was performed. No graft loss or anastomotic leakage was observed, and the postoperative course was uneventful in the cases of jejunal reconstruction. For ileocolic reconstruction, however, 1 patient developed an intrathoracic abscess that required computed tomography-guided drainage, and 1 patient had a persistent pulmonary fistula, which was successfully managed conservatively (Table 2). Swallowing function remained unchanged before and after surgery in the 2 patients with laryngeal preservation, and no aspiration was detected. Postoperative contrast studies showed good passage and 


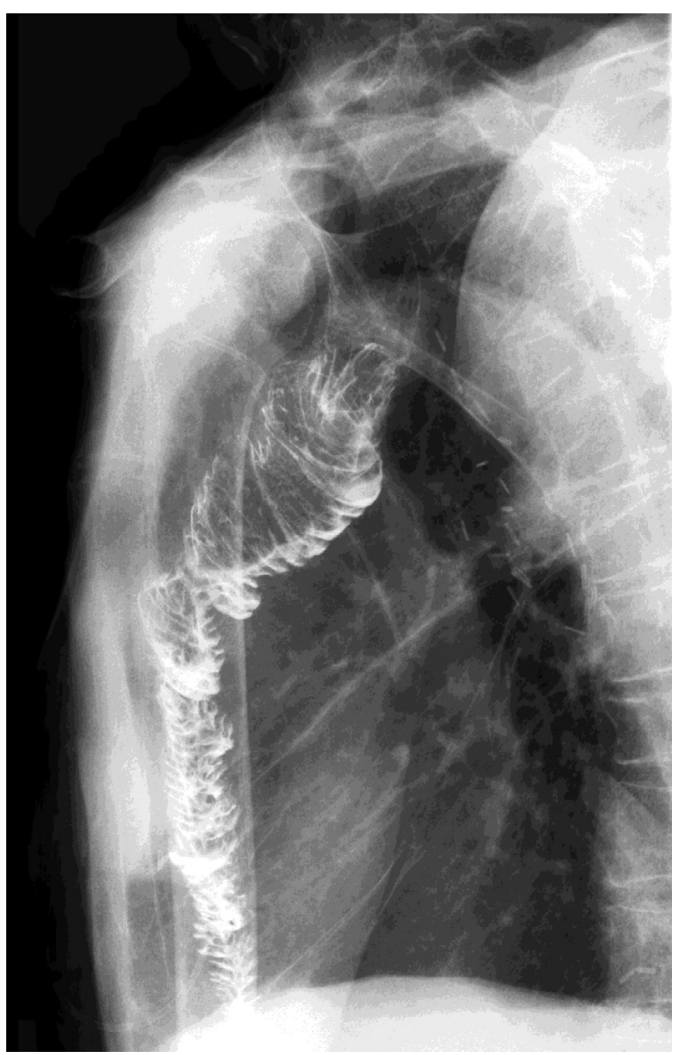

FIGURE 6. Contrast study image showing good passage in the graft in patient 3 .

no retention of food in the pull-up graft. There were no inhospital deaths, and all patients were discharged to home without being transferred to another hospital.

\section{Progress After Discharge}

Patient 4 developed multiple lung and liver metastases 6 months after surgery and died 1 month later. However, his dietary intake and activities of daily living remained satisfactory until 2 weeks before his death. At the time of this report, the remaining 3 patients have shown no recurrence at 3, 4, and 8 years postoperatively, remaining in good general condition and showing no deterioration of swallowing function or food passage.

\section{DISCUSSION}

This novel esophageal reconstruction technique that uses a jejunal or colonic graft, which can be termed "transmediastinal reconstruction," involves pulling up the graft through the AM route with a high intrathoracic anastomosis in the PM, enabling the addition of microvascular anastomosis. To our knowledge, no previous reports have described a technique of hybrid esophageal reconstruction like ours.

Surgery for esophageal cancer remains one of the most challenging surgeries, with the highest surgical stress and risk. Operative mortality (ie, death within 30 days after operation) is reported to be $2.5 \%$ in $\mathrm{Japan}^{3}$ and $3.1 \%$ in the United States, ${ }^{12}$ with morbidity of $34 \%-43 \%$ reported in Japan. ${ }^{13,14}$ Recent studies have pointed out that postoperative complications are likely to worsen the prognosis, ${ }^{13,14}$ and thus measures to reduce surgical risk and postoperative complications are vital. In the relatively large numbers of ESCC patients with a previous history of surgery for $\mathrm{HNC},{ }^{1,2}$ adding the cervical procedure likely increases the surgical risk. In addition, with the

TABLE 1. Preoperative patient characteristics

\begin{tabular}{|c|c|c|c|c|c|c|c|c|c|}
\hline \multirow[b]{2}{*}{ Patient } & \multirow[b]{2}{*}{ Age, $y$} & \multirow[b]{2}{*}{ Sex } & \multicolumn{5}{|c|}{ Past medical history } & \multirow[b]{2}{*}{$\begin{array}{c}\text { Present } \\
\text { disease }(y) \text {, location } \\
\text { and cStage }\end{array}$} & \multirow[b]{2}{*}{$\begin{array}{l}\text { Preoperative } \\
\text { therapy }\end{array}$} \\
\hline & & & $\begin{array}{c}\text { Disease of } \\
\text { previous } \\
\text { gastrectomy }(\mathbf{y})\end{array}$ & $\begin{array}{c}\text { Surgical } \\
\text { procedure }\end{array}$ & $\begin{array}{l}\text { History of other } \\
\text { surgery }(y)\end{array}$ & $\begin{array}{l}\text { History of } \\
\text { other } \\
\text { treatment }\end{array}$ & $\begin{array}{l}\text { Tracheal } \\
\text { stoma }\end{array}$ & & \\
\hline 1 & 63 & Female & $\begin{array}{l}\text { GC } \\
\text { (2006) }\end{array}$ & $\begin{array}{l}\text { Distal } \\
\quad \text { gastrectomy }+ \\
\text { B-I }\end{array}$ & $\begin{array}{l}\text { Ce SCC (pT4N1M0, } \\
\text { pStage IIIC) } \rightarrow \text { free } \\
\text { jejunal transfer } \\
(2006)\end{array}$ & $\begin{array}{l}\text { Preoperative and } \\
\text { postop CRT } \\
(30 \mathrm{~Gy}+30 \mathrm{~Gy}) \\
\text { for Ce SCC }\end{array}$ & + & $\begin{array}{l}\text { Te SCC (2009) Lt } \\
\text { cT1bN0M0, } \\
\text { cStage IA }\end{array}$ & None \\
\hline 2 & 71 & Male & GU (1973) & $\begin{array}{l}\text { Distal } \\
\text { gastrectomy }+ \\
\text { B-I }\end{array}$ & $\begin{array}{l}\text { Laryngeal cancer } \rightarrow \\
\text { laryngectomy } \\
\text { (2001); lung } \\
\text { tuberculoma } \rightarrow \text { rt } \\
\text { lung partial } \\
\text { resection (2008) }\end{array}$ & $\begin{array}{l}\text { MC flap repair } \\
\text { for postoperative } \\
\text { skin fistula }\end{array}$ & + & $\begin{array}{l}\text { Te SCC (2013) } \\
\text { Mt-Lt cT3N1M0, } \\
\text { cStage IIIA }\end{array}$ & $\begin{array}{l}\text { DCF for } 1 \\
\text { course and } \\
\text { DNF for } 2 \\
\text { courses }\end{array}$ \\
\hline 3 & 69 & Male & GC (2009) & $\begin{array}{l}\text { Total } \\
\quad \text { gastrectomy }+ \\
\text { Roux-en Y }\end{array}$ & & & + & $\begin{array}{l}\text { Recurrence of GC } \\
\text { above the site of } \\
\text { esophagojejunostomy } \\
\text { (2014) }\end{array}$ & None \\
\hline 4 & 83 & Male & GC (2008) & $\begin{array}{l}\text { Distal gastrectomy }+ \\
\quad \text { B-I }\end{array}$ & & & + & $\begin{array}{l}\text { Te SCC (2014) } \\
\text { Lt cT3N0M0, } \\
\text { cStage IIA }\end{array}$ & None \\
\hline
\end{tabular}

$G C$, Gastric cancer; $B$-I, Billroth-I; $C e$, cervical esophagus; $S C C$, squamous cell carcinoma; $C R T$, chemoradiotherapy; $T e$, thoracic esophagus; $M t$ and $L t$, middle and lower thirds of the thoracic esophagus; $G U$, gastric ulcer; $M C$, musculocutaneous; $D C F$, docetaxel + cisplarin +5 -fulorouracil; $D N F$, docetaxel + nedaplatin +5 -fulorouracil. 
TABLE 2. Surgical outcomes

\begin{tabular}{|c|c|c|c|c|c|c|}
\hline \multirow{3}{*}{$\frac{\text { Patient }}{1}$} & \multicolumn{4}{|c|}{ Surgical procedure } & \multirow{3}{*}{$\begin{array}{c}\text { Pathological findings } \\
\text { Poorly differentiated } \\
\text { SCC, pT1bN0M0 }\end{array}$} & \multirow{3}{*}{$\begin{array}{c}\text { Postoperative } \\
\text { complications }\end{array}$} \\
\hline & $\begin{array}{c}\text { Reconstruction } \\
\text { organ }\end{array}$ & $\begin{array}{l}\text { Microvessel } \\
\text { anastomosis }\end{array}$ & \multicolumn{2}{|c|}{ Anastomotic method } & & \\
\hline & $\begin{array}{l}\text { Ileum and right- } \\
\text { side colon }\end{array}$ & $\begin{array}{l}\text { rt ITA }+\mathrm{V} \leftrightarrow \text { ileocolic } \\
\quad \mathrm{A}+\mathrm{V}\end{array}$ & $\begin{array}{c}\text { Hand-sewn } \\
\text { with AL }\end{array}$ & $\begin{array}{l}\text { End-to end } \\
\text { jejunoileostomy }\end{array}$ & & \\
\hline 2 & $\begin{array}{l}\text { Ileum and right- } \\
\text { side colon }\end{array}$ & $\begin{array}{c}\text { rt ITA }+\mathrm{V} \leftrightarrow \text { ileac } \\
\text { marginal } \mathrm{A}+\mathrm{V}\end{array}$ & $\begin{array}{l}\text { Circular stapler } \\
\text { (PCEEA25) }\end{array}$ & $\begin{array}{l}\text { End-to-side } \\
\text { esophagoileostomy }\end{array}$ & $\begin{array}{l}\text { Well- differentiated SCC, } \\
\text { pT3N1M0 }\end{array}$ & $\begin{array}{l}\text { Pulmonary } \\
\text { fistula }\end{array}$ \\
\hline 3 & Pedicled jejunum & $\begin{array}{l}\mathrm{rt} \mathrm{ITA}+\mathrm{V} \leftrightarrow \mathrm{J} 1 \\
\mathrm{~A}+\mathrm{V}\end{array}$ & $\begin{array}{l}\text { Circular stapler } \\
\text { (PCEEA25) }\end{array}$ & $\begin{array}{l}\text { End-to-side } \\
\text { esophagojejunostomy }\end{array}$ & $\begin{array}{l}\text { Poorly differentiated } \\
\text { adenocarcinoma, } \\
\text { pT3N1M0 }\end{array}$ & - \\
\hline 4 & Pedicled jejunum & $\begin{array}{l}\mathrm{rt} \mathrm{ITA}+\mathrm{V} \leftrightarrow \mathrm{J} 2 \\
\mathrm{~A}+\mathrm{V}\end{array}$ & $\begin{array}{l}\text { Circular stapler } \\
\quad(\mathrm{CDH} 25)\end{array}$ & $\begin{array}{l}\text { End-to-side } \\
\text { esophagojejunostomy }\end{array}$ & $\begin{array}{l}\text { Moderately differentiated } \\
\text { SCC, } \\
\text { pT3N1M0 }\end{array}$ & - \\
\hline
\end{tabular}

$r t$, Right; $I T A$, internal thoracic artery; $V$, vein; $A$, artery; $A L$, Albert-Lembert; $S C C$, squamous cell carcinoma; $J$, jejunal.

aging population, the number of elderly patients with ESCC has been increasing, most of whom are at potential risk for aspiration, especially after stroke. ${ }^{4,5}$ Consequently, avoiding cervical procedures in such patients is important both for decreasing surgical risk and maintaining swallowing function by preserving the cervical muscles. In fact, postoperative swallowing rehabilitation was not needed in our 4 patients, all of whom subsequently resumed a regular diet.

The novelty of this surgical procedure lies in the ability to perform microvascular anastomosis in an intrathoracic anastomosis, as is usually performed in conventional posterior mediastinal reconstruction. The need for microvascular anastomosis remains controversial, however. Some researchers have reported that microvascular anastomosis is not always required, even in jejunal or colonic reconstruction with intrathoracic anastomosis in the upper mediastinum. $^{15,16}$ In addition, the procedure is not always effective in preventing anastomotic failure, with a reported incidence of leakage of $7 \%$ to $46 \%$ in colonic reconstruction and $10.3 \%$ to $36.4 \%$ in jejunal reconstruction. ${ }^{10,11}$ However, graft loss is rarely observed in cases with microvascular anastomosis, with no graft loss in colonic reconstructions and graft loss in only 3 of $182(1.6 \%)$ jejunal reconstructions. Given these results and the major difficulties associated with reoperation for postoperative complications in the target populations, microvascular anastomosis is useful to prevent graft loss, leading to reduced surgical risk.

Nevertheless, our novel reconstruction technique has several disadvantages. First, temporary chest closure after completion of esophagectomy and repeat thoracotomy in reconstruction are needed, which tends to lead to prolonged operative time. Second, after completion of the first thoracic procedure, the patient is placed in the left half side-lying position to reduce the need for position changes, which is burdensome for setup. Third, it can be very challenging to determine which costal cartilage should be resected to make a microvascular anastomosis with the right ITVs. However, this does not need to be pinpointed exactly; the right ITVs can be exposed over a length of several centimeters by resecting the upper and lower intercostal muscles together with the costal cartilage, and then harvested as graft vessels with a long pedicle. This provides a wide allowable range for the microvascular anastomosis site.

The present study also has some limitations. We performed this new esophageal reconstruction in only 4 patients, and the postoperative follow-up period is currently less than 4 years, except for 1 patient with 8 years of follow-up. Therefore, we will continue to accumulate experience with this new surgical technique, ensuring careful patient selection and examining its usefulness by evaluating the long-term function of the replacement conduit in terms of motility, digestion, absorption, and nutrition.

In conclusion, we have designed a novel transmediastinal esophageal reconstruction method placing the jejunal or colonic graft crossing the mediastinum from the PA to the $\mathrm{AM}$ in gastrectomized patients. This is a unique surgical procedure that preserves swallowing function by avoiding cervical procedures while simultaneously securing the blood supply of the graft with microvascular anastomosis even in an intrathoracic anastomosis in the PM and reducing surgical risk. However, given its several disadvantages, this technique should be used only in highly selected patients, not as a standard or as an alternative modality when the graft is found to be ischemic after preparation.

\section{Conflict of Interest Statement}

Authors have nothing to disclose with regard to commercial support.

\section{References} 1. Su YY, Chen WC, Chuang HC, Guo CS, Lin YT, Luo SD, et al. Effect of routine
esophageal screening in patients with head and neck cancer. JAMA Otolaryngol
Head Neck Surg. 2013;139:350-4. 
2. Tachimori Y, Ozawa S, Numasaki H, Ishihara R, Matsubara H, Muro K, et al. Clinical factors of esophageal cancer patients treated in 2010. In: The Registry Committee for Esophageal Cancer of the Japan Esophageal Society, ed. Comprehensive Registry of Esophageal Cancer in Japan, 2010. Tokyo: Editorial Office of The Japan Esophageal Society; 2017:1-9.

3. Tachimori Y, Ozawa S, Numasaki H, Ishihara R, Matsubara H, Muro K, et al; The Registration Committee for Esophageal Cancer of the Japan Esophageal Society. Comprehensive registry of esophageal cancer in Japan, 2010. Esophagus. 2017; 14:189-214.

4. Nakagawa T, Sekizawa K, Arai H, Kikuchi R, Manabe K, Sasaki H. High incidence of pneumonia in elderly patients with basal ganglia infarction. Arch Intern Med. 1997;157:321-4.

5. Uehara T, Tabuchi M, Mori E. Risk factors for silent cerebral infarcts in subcortical white matter and basal ganglia. Stroke. 1999;30:378-82.

6. Nakazawa H, Sekizawa K, Ujiie Y, Sasaki H, Takishima T. Risk of aspiration pneumonia in the elderly. Chest. 1993;103:1636-7.

7. Ebihara S, Ebihara T, Kohzuki M. Effect of aging on cough and swallowing reflexes: implications for preventing aspiration pneumonia. Lung. 2012;190:29-33.

8. Hambraeus GM, Ekberg O, Fletcher R. Pharyngeal dysfunction after total and subtotal oesophagectomy. Acta Radiol. 1987;28:409-13.

9. Leder SB, Bayer S, Sasaki CT, Salem RR. Fiberoptic endoscopic evaluation of swallowing in assessing aspiration after transhiatal esophagectomy. J Am Coll Surg. 2007;205:581-5.

10. Yasuda T, Shiozaki H. Esophageal reconstruction using a pedicled jejunum with microvascular augmentation. Ann Thorac Cardiovasc Surg. 2011;17:103-9.
11. Yasuda T, Shiozaki H. Esophageal reconstruction with colon tissue. Surg Today. 2011:41:745-53.

12. Raymond DP, Seder CW, Wright CD, Magee MJ, Kosinski AS, Cassivi SD, et al. Predictors of major morbidity or mortality after resection for esophageal cancer: a Society of Thoracic Surgeons general thoracic surgery database risk adjustment model. Ann Thorac Surg. 2016;102:207-14.

13. Kataoka K, Takeuchi H, Mizusawa J, Igaki H, Ozawa S, Abe T, et al. Prognostic impact of postoperative morbidity after esophagectomy for esophageal cancer: exploratory analysis of JCOG9907. Ann Surg. 2017; 265:1152-7.

14. Baba Y, Yoshida N, Shigaki H, Iwatsuki M, Miyamoto Y, Sakamoto Y, et al. Prognostic impact of postoperative complications in 502 patients with surgically resected esophageal squamous cell carcinoma: a retrospective single-institution study. Ann Surg. 2016;264:305-11.

15. Ninomiya I, Okamoto K, Oyama K, Hayashi H, Miyashita T, Tajima H, et al. Feasibility of esophageal reconstruction using a pedicled jejunum with intrathoracic esophagojejunostomy in the upper mediastinum for esophageal cancer. Gen Thorac Cardiovasc Surg. 2014;62:627-34.

16. Mine S, Udagawa H, Tsutsumi K, Kinoshita Y, Ueno M, Ehara K, et al. Colon interposition after esophagectomy with extended lymphadenectomy for esophageal cancer. Ann Thorac Surg. 2009;88:1647-54.

Key Words: esophageal reconstruction, intrathoracic anastomosis, microvascular anastomosis

Readers who found these articles interesting may also like to read the following papers found in recent and future issues of our sister publications, Seminars in Thoracic and Cardiovascular Surgery and Operative Techniques in Thoracic and Cardiovascular Surgery!

\section{Thoracic: Esophageal Cancer}

ORIGINAL SUBMISSION: Esophagectomy in Patients with Human Immunodeficiency Virus and Acquired Immune Deficiency Syndrome: A Viable Option. Michael Mwachiro. Semin Thoracic Surg 2018:116-121 